\title{
Remodeling of Synaptic AMPA Receptor Subtype Alters the Probability and Pattern of Action Potential Firing
}

\author{
Iaroslav Savtchouk and Siqiong June Liu \\ Department of Cell Biology and Anatomy, Louisiana State University Health Sciences Center, New Orleans, Louisiana 70112, and Department of Biology, \\ Pennsylvania State University, University Park, Pennsylvania 16802
}

Changes in the subunit composition of postsynaptic AMPA-type glutamate receptors can be induced at CNS synapses by neural activity and under certain pathological conditions. Fear-induced incorporation of GluR2-containing receptors at cerebellar synapses selectively prolongs the decay time of synaptic currents, whereas a switch from GluR2-lacking to GluR2-containing receptors induced by parallel fiber stimulation reduces the amplitude in addition to lengthening the duration of EPSCs. Although it is often assumed that these two forms of synaptic plasticity will alter action potential (AP) firing in the postsynaptic neuron, this has not been directly tested. Using a dynamic current-clamp approach, we now show that the fear-induced increase in EPSC duration increases the size of EPSPs and thereby markedly enhances the AP firing probability. In contrast, the parallel fiber stimulation-triggered switch in GluR2 expression reduces the EPSP-AP coupling because of the decrease in the synaptic current amplitude. The switch also abolished the paired-pulse facilitation that arose from an activity and spermine-dependent unblock of GluR2-lacking receptors and hence reduced the ability of paired stimuli to evoke two consecutive APs. Therefore, fear-induced incorporation of GluR2 receptors enhances the EPSP-AP coupling, but the parallel fiber stimulation-triggered switch reduces both the EPSP-AP coupling and evoked AP doublets. In contrast to long-term potentiation and depression, which modify the amplitude of synaptic currents, this activity-induced change in AMPA receptor phenotype alters synaptic conductance waveform and postsynaptic short-term plasticity. These changes modulate both the probability and pattern of evoked AP firing via a fundamentally different mechanism from long-term potentiation and long-term depression.

\section{Introduction}

Experience-induced modifications of synaptic transmission can alter information processing within a neuronal circuit. The best understood postsynaptic modification involves a change in the number or phosphorylation state of AMPA receptors (AMPARs), so altering the amplitude of the synaptic current and giving rise to longterm potentiation and depression (Barry and Ziff, 2002; Malinow and Malenka, 2002; Song and Huganir, 2002). However, neuronal activity can also alter the subunit composition of synaptic AMPARs and thereby change the kinetics of the synaptic current (Geiger et al., 1995). The most commonly observed AMPAR subtype remodeling involves changes in the abundance of GluR2 subunits. Such changes can occur after repetitive synaptic stimulation, sensory deprivation, emotional stress, drug addiction, and under certain pathological conditions, such as epilepsy (Fitzgerald et al., 1996; Grooms et al., 2000; Liu and Cull-Candy, 2000; Opitz et al., 2000; Bellone and Lüscher, 2006; Clem and Barth, 2006; Goel et al., 2006). Therefore, it is critical to determine the functional consequences of the

Received May 21, 2010; revised 0ct. 15, 2010; accepted 0ct. 25, 2010.

This work was supported by National Science Foundation Grant IBN-0964517 and National Institutes of Health Grant NS58867 (S.J.L.). We thank Drs. Matthew Whim, Philippe Lachamp, Yu Liu, and Lu Sun for helpful discussions and comments on this manuscript.

Correspondence should be addressed to Dr. Siqiong June Liu, Department of Cell Biology and Anatomy, Louisiana State University Health Sciences Center, New Orleans, LA 70112. E-mail: sliu@|suhsc.edu.

D01:10.1523/JNEUROSCI.2608-10.2011

Copyright $\odot 2011$ the authors $\quad 0270-6474 / 11 / 310501-11 \$ 15.00 / 0$
AMPAR phenotype change on signal transmission in a neuronal network.

The waveform of the synaptic current is a key element that shapes the EPSP (Trussell, 1998). Inhibitory interneurons often express $\mathrm{Ca}^{2+}$-permeable GluR2-lacking AMPARs that exhibit several unusual features (Cull-Candy et al., 2006; Isaac et al., 2007; Liu and Zukin, 2007). First, the synaptic current of these neurons displays particularly fast kinetics. We have recently found that stress can enhance GluR2 gene expression in cerebellar stellate cells and selectively prolongs the decay time of synaptic currents (Liu et al., 2010). The second characteristic of GluR2lacking AMPARs is the paired-pulse facilitation that arises from an intracellular polyamine blockade and that can be released in a use-dependent manner (Rozov and Burnashev, 1999). Given these characteristics, we would expect that an activity-dependent switch in AMPAR subtype would abolish postsynaptic shortterm plasticity. Cerebellar stellate cells are electrically compact and the activation of single parallel fiber (PF) inputs can strongly influence stellate cell firing (Carter and Regehr, 2002). The activity-induced change in current amplitude, kinetics, and facilitation that results from the switch in AMPAR subtype would thus be predicted to alter the efficacy of EPSP-action potential (AP) coupling in stellate cells and to influence the timing and firing frequency of Purkinje cells, which are the only cortical output.

The present study was undertaken to determine whether synaptic AMPAR subtype remodeling by two physiologically relevant stimuli (emotional stress and repetitive parallel fiber 
stimulation) actually does lead to an alteration in the AP firing of stellate cells. We found that the AMPAR subtype remodeling alters both the probability and the pattern of evoked APs in stellate cells. Unexpectedly, these two stimuli had different effects on AP firing. The emotional arousal-induced incorporation of GluR2 receptors potentiated AP firing, whereas the parallel fiber stimulation-induced switch in AMPAR phenotype suppressed AP firing and reduced the ability of paired stimuli to evoke two consecutive APs. Thus, a bidirectional alteration in the AP probability and pattern that results from AMPAR subtype remodeling strongly depends on the nature of the stimulus.

\section{Materials and Methods}

Slice preparation and recordings. Horizontal and sagittal slices $(250 \mu \mathrm{m})$ were cut from cerebella of C57BL/6J mice at postnatal day 18 (P18) to P22 on a Leica VT1000S vibrating microslicer in ice-cold slicing solution (in mM: $125 \mathrm{NaCl}, 2.5 \mathrm{KCl}, 1 \mathrm{CaCl}_{2}, 7 \mathrm{MgCl}_{2}, 1.25 \mathrm{NaH}_{2} \mathrm{PO}_{4}, 26$ $\mathrm{NaHCO}_{3}$, and 25 glucose, $\mathrm{pH} 7.4$, with a $5 \% \mathrm{CO}_{2} / 95 \% \mathrm{O}_{2}$ mix). Stellate cells located in the outer two-thirds of the molecular layer were visually identified using differential interference contrast with a $60 \times$ waterimmersion objective. Stellate cells were identified by their spontaneous action potential firing (in cell-attached mode) and by the presence of spontaneous synaptic currents (in whole-cell mode). All recordings were performed at near physiological temperature $\left(34-37^{\circ} \mathrm{C}\right)$ unless otherwise indicated.

Electrophysiology. Voltage and dynamic current-clamp recordings were made using an Axopatch 700A or a 200B amplifier (Molecular Devices). Recordings were low-pass filtered at $10 \mathrm{kHz}$ and digitized at 20 $\mathrm{kHz}$. Whole-cell recordings were performed using 5-7 $\mathrm{M} \Omega$ borosilicate glass pipettes.

Voltage-clamp recordings. All voltage-clamp experiments were performed using a cesium-based internal solution [in mM: $135 \mathrm{CsCl}, 10$ EGTA-Cs, 10 HEPES, 4 ATP-Na, $4 \mathrm{MgCl}_{2}$, 5 TEA, 1 lidocaine $N$-ethyl bromide (QX-314), and 0.1 spermine; $\mathrm{pH}$ adjusted to 7.3 with $1 \mathrm{M}$ $\mathrm{CsOH}$ ]. Spermine $(0.1 \mathrm{~mm})$ was included in the patch electrode to block GluR2-lacking AMPA receptors at depolarized potentials and was used to determine the subunit composition of synaptic AMPA receptors. The series resistance was monitored throughout the experiment. The collected data were not used if the value changed by $>20 \%$.

To characterize the properties of unitary synaptic currents mediated by GluR2-lacking and GluR2-containing receptors, spontaneous EPSCs (sEPSCs) were determined at various holding potentials before, and after, parallel fiber stimulation, which was delivered via a bipolar electrode placed across the molecular layer. The stimulation protocol consisted of 10 repetitions of four pulses $(12 \mathrm{~V}, 200 \mu \mathrm{s})$ at $50 \mathrm{~Hz}$, every $2 \mathrm{~s}$. The average EPSC waveform and $I-V$ relationship were constructed as previously described (Liu and Cull-Candy, 2000). The cells were voltageclamped at $-70 \mathrm{mV}(n=3)$ or at $-30 \mathrm{mV}(n=2)$ during the burst stimulation. The decay time constants of spontaneous EPSCs were obtained by fitting the decay phase of individual EPSC events with single- and doubleexponential decay functions. The weighted decay time constants were similar to those obtained with a single-exponential fit.

To determine whether the switch in AMPAR subtype is associated with a change in paired-pulse facilitation, EPSCs were evoked by a focal threshold stimulation of parallel fibers using a 100-200 $\mu$ s voltage pulse $(5-15 \mathrm{~V})$ delivered via a monopolar electrode (5-7 M $\Omega$ ) positioned $\sim 100 \mu \mathrm{m}$ from the cell. Paired pulses were delivered at a $10 \mathrm{~ms}$ interval. The evoked EPSCs were measured at -60 and $+40 \mathrm{mV}$ before and 15 min after high-frequency parallel fiber stimulation (three trains of 100 pulses at $50 \mathrm{~Hz}$ each, every $20 \mathrm{~s}$ ) performed at $-60 \mathrm{mV}$ and at room temperature. Short-term postsynaptic facilitation was characterized by the postsynaptic paired-pulse ratio (PPR). To remove any presynaptic contribution, each current trace was reviewed to remove failures and multiple peak events, and each EPSC was manually aligned based on the current rise time using N, version 4.0 (written by Stephen Traynelis, Emory University, Atlanta, GA). Postsynaptic paired-pulse ratio was calculated by dividing the amplitude of the average current evoked by pulse 2 by the average current evoked by pulse 1 .
Dynamic current-clamp experiments. Action potentials were recorded in current-clamp mode while injecting small negative currents of up to $-30 \mathrm{pA}$ to keep the membrane potential at -60 to $-70 \mathrm{mV}$. Action potentials were recorded using a potassium-based internal solution containing the following (in mM): $115 \mathrm{KMeSO}_{3}, 10 \mathrm{HEPES}, 0.5 \mathrm{~K}-\mathrm{EGTA}, 0.16 \mathrm{CaCl}_{2}, 2 \mathrm{MgCl}_{2}, 10$ $\mathrm{NaCl}, 4$ ATP-Na, 14 Tris-creatine phosphate, 0.4 GTP-Na. Series resistance was periodically monitored, and the data were discarded if this changed by $>40 \%$. All recordings were performed in the presence of $200 \mu \mathrm{M}$ picrotoxin and either 2-5 mM kynurenic acid or $10 \mu \mathrm{M}$ NBQX [6-nitro-7-sulfamoyl$\operatorname{benzo}(f)$ quinoxaline-2,3-dione] and $10 \mu \mathrm{M}$ 4-(3-phosphonopropy1)piperazine-2-carboxylic acid $[(R)-C P P]$ to block inhibitory and glutamatergic synaptic transmission. Cells were not used if the amplitude of action potentials was $<40 \mathrm{mV}$. The geometric mean of the capacitance of stellate cells was $5.96 \mathrm{pF}(n=321$; geometric SD, 1.47) when fitted with a log normal distribution. Therefore, cells with a capacitance between 2.74 and $12.9 \mathrm{pF}($ mean $\pm 2 \mathrm{SD})$ were included in our analysis.

For artificial synaptic event delivery, an SM-1 analog computer was used in combination with an Axopatch 700A or 200B amplifier and a Digidata 1320 digitizer. Conductance templates were constructed by dividing the recorded current traces by the membrane potential under voltage-clamp recording. The SM-1 used the membrane voltage provided by the amplifier and the conductance template from the Digidata 1320 to modify the command current. To minimize the effect of systematic changes, conductance templates were applied at $1 \mathrm{~Hz}$ and different conductance template waveforms were alternated throughout the recording. The cell response was determined by counting the number of action potentials evoked by the template within a $20 \mathrm{~ms}$ window starting at the time of injection or within a 10 and $60 \mathrm{~ms}$ window for paired conductance waveforms. In some cells, $0.3 \mu \mathrm{M}$ TTX was added to record the passive EPSP response to injected conductances.

Fox urine treatment. Fox urine treatment was performed as previously described (Kopec et al., 2007). The mouse was placed inside a plastic cage $(16 \times 9 \times 6$ inch $)$ with an elevated floor containing regularly spaced small openings. After $3 \mathrm{~min}$, a paper towel soaked in $5 \mathrm{ml}$ of fox urine was placed under the floor for $5 \mathrm{~min}$ (Liu et al., 2010).

Chemical reagents. Fox urine was obtained from Green Sense Organic Gardening, ( $R$-CPP from Tocris Bioscience, Tris-creatine phosphate and sodium ATP from Sigma-Aldrich, potassium methylsulfonate from Alfa Aesar, sodium GTP from Calbiochem, spermine from MP Biomedicals, picrotoxin from Indofine, and kynurenic acid and QX-314 from Ascent.

A two-tailed Student's paired $t$ test, ANOVA, and Kolmogorov-Smirnov test were used as indicated. All data are presented as mean \pm SEM.

\section{Results}

\section{A stress-induced increase in EPSC duration enhances EPSP-AP coupling}

AMPARs lacking GluR2 subunits are present at the parallel fiber to stellate cell synapse (Liu and Cull-Candy, 2000). In a recent study, we have found that a fear-inducing stressor enhances GluR2 gene transcription and promotes the expression of synaptic GluR2-containing AMPARs in stellate cells (Liu et al., 2010). Here, we investigated the functional consequences of the fear-induced change in AMPAR subtype. We exposed mice to fox urine for $5 \mathrm{~min}$, a paradigm that induces a fear response, and then monitored spontaneous EPSCs at the stellate cell synapse in cerebellar slices taken from mice $15 \mathrm{~h}$ later. $N, N, H$-Trimethyl-5-[(tricyclo[3.3.1.13,7] dec-1-ylmethyl)amino]1-pentanaminiumbromide hydrobromide (IEM-1460), a $\mathrm{Ca}^{2+}$. permeable AMPAR blocker, was used to determine the subunit composition of synaptic AMPARs. In control cells, application of IEM-1460 $(100 \mu \mathrm{M})$ blocked the EPSC amplitude at $-60 \mathrm{mV}$ by $\sim 60 \%$ ( $n=3$ cells from 3 control mice) (Fig. $1 A$ ). At $15 \mathrm{~h}$, after fox urine exposure, the degree of inhibition by IEM-1460 was significantly reduced ( $36 \pm 9 \% ; n=3$ cells from 3 fox urine-treated mice; $p<0.05$ ) (Fig. 1A). These data suggest that a single exposure to a fear-inducing stimulus alters the AMPAR subtype from GluR2lacking to GluR2-containing at the parallel fiber-to-stellate cell synapse. 
A

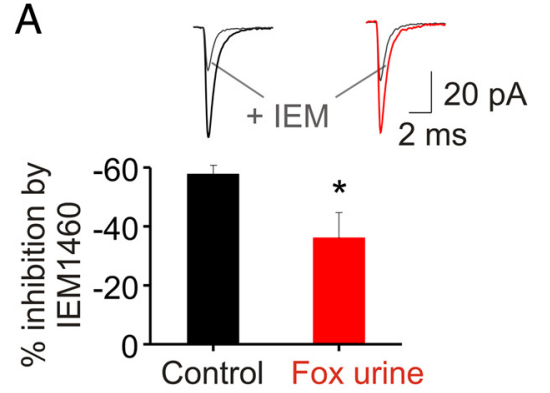

C

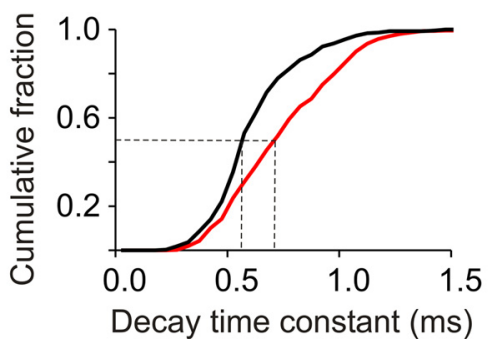

B

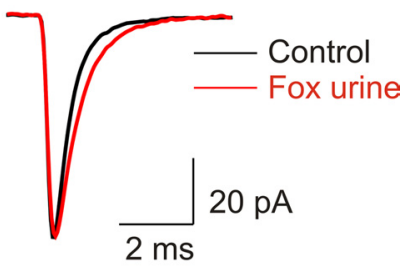

D

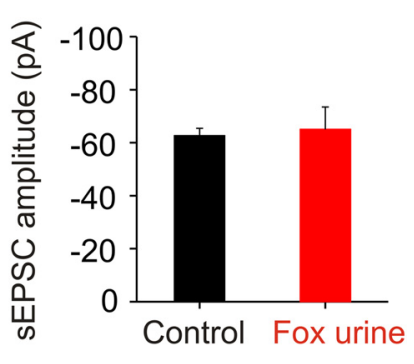

Figure 1. Emotional stress prolonged EPSC decay time without changing the current amplitude in stellate cells. $\boldsymbol{A}$, Mice were exposed to fox urine for $5 \mathrm{~min}$ to elicit a fear response. EPSCs were measured at $36^{\circ} \mathrm{C} 15 \mathrm{~h}$ after a mouse was exposed to fox urine. Inhibition of EPSCS at $-60 \mathrm{mV}$ by IEM-1460 $(100 \mu \mathrm{M})$, a selective $\mathrm{Ca}^{2+}$-permeable AMPAR blocker, was reduced after fox urine exposure ( $n=3$ cells from 3 different mice in each group; $p<0.05$ ). $\boldsymbol{B}$, Example showing the increase in decay time of average sEPSCs after fox urine exposure. $C$, Median decay time constant of individual sEPSCs increases from 0.57 to $0.71 \mathrm{~ms}$ after fox urine exposure (control, 562 synaptic events, $n=7$ cells from 7 mice; fox urine treated, 558 events, $n=6$ cells from 3 mice; $p<$ 0.00001 , Kolmogorov-Smirnov test). D, Average sEPSC amplitude did not change after fox urine exposure (control, $n=7$; fox urine treated, $n=6 ; p>0.05$, unpaired $t$ test). Error bars indicate SEM. ${ }^{*} p<0.05$.

To examine the impact of the change in synaptic AMPAR phenotype on the kinetics of EPSCs, we measured the decay time constant of spontaneous EPSCs at $-60 \mathrm{mV}$ at $36^{\circ} \mathrm{C}$ in cerebellar stellate cells (Fig. 1B). This allowed us to determine the properties of the quantal synaptic currents, and to sample synaptic currents from a large number of synapses. Fox urine exposure significantly prolonged the decay time of EPSCs (control, 562 individual EPSCs from 7 cells; fox urine, 558 events from 6 cells; $p<0.00001$, by Kolmogorov-Smirnov test) (Fig. 1C). However the amplitude of synaptic currents at $-60 \mathrm{mV}$ in stellate cells from mice that were briefly exposed to fox urine was indistinguishable from control (control: $-62.7 \pm 2.8 \mathrm{pA}, n=7 ; 15 \mathrm{~h}$ after fear-inducing stimulus: $-65.0 \pm 8.4 \mathrm{pA}, n=6$ ) (Fig. $1 D$ ). The average conductance of somatic AMPAR channels was $30 \%$ smaller in stellate cells expressing predominantly $\mathrm{Ca}^{2+}$ impermeable AMPARs than in those having a mixed population of GluR2-containing and -lacking receptors (Liu and CullCandy, 2005). Thus, the total number of synaptic receptors is estimated to increase by $36 \%$ after fear stimulus. A mixture of receptors is predicted to give rise to a synaptic current that contains both fast and slow components mediated by GluR2-lacking and -containing receptors, respectively. Indeed, when fitted with a two-exponential function, the fast component comprised $\sim 60 \%$ control EPSCs, but only $\sim 30 \%$ of the total synaptic current after fear-inducing stimulus $(p=0.13)$. These results suggest that fear stimulus markedly promotes the synaptic incorporation of additional GluR2-containing receptors and moderately reduces GluR2lacking receptors, giving rise to a prolonged EPSC decay time and unaltered EPSC amplitude.

Using the dynamic current-clamp technique, we next examined the effects of the prolonged EPSC decay time on the wave- form of EPSPs in stellate cells. We constructed conductance templates to mimic the synaptic current in control and after emotional stress. These templates had the same rise time as the control quantal events, but with a singleexponential decay phase with time constants of 0.5 and $0.7 \mathrm{~ms}$ (which corresponds to the median decay time constants of EPSCs in control and after emotional stress, respectively) (Fig. 1C) and an amplitude of double the unitary conductance. We reasoned that the prolonged decay kinetics would allow a greater number of ions to enter the cell and would evoke a larger EPSP. To test this possibility, we injected these conductance templates into stellate cells and measured membrane potentials in the presence of TTX (to block Na channels). Indeed prolongation of the EPSC decay kinetics from 0.5 to $0.7 \mathrm{~ms}$ gave rise to an increase in the EPSP amplitude $(9.6 \pm 0.7$ vs $11.1 \pm 0.8 \mathrm{mV} ; n=4 ; p<0.0005$ ) (Fig. $2 A)$. To determine the effect of the prolonged EPSC decay time on the ability to evoke action potentials, we injected the conductance templates into stellate cells and monitored the membrane potential in the absence of TTX. Increasing the EPSC decay kinetics from 0.5 to $0.7 \mathrm{~ms}$ resulted in a marked increase in the evoked AP probability from $0.42 \pm 0.08$ to $0.62 \pm 0.08(n=7$; $p<0.005$ ) (Fig. $2 A-C$ ). Note that a small increase in decay time is sufficient to alter EPSP amplitude and leads to enhanced AP firing in stellate cells. Thus, the change in decay time associated with the insertion of GluR2 receptors markedly promotes EPSP-AP coupling in stellate cells.

To determine the dynamic range over which EPSC decay time alters AP firing probability, we tested a series of templates that covered the distribution of decay time constants of naturally occurring synaptic events that were recorded under physiological conditions. These ranged from 0.3 to $1.1 \mathrm{~ms}$ in steps of $0.2 \mathrm{~ms}$ (Fig. 1C). As shown in Figure 2, $B$ and $C$, prolonging the EPSC decay time markedly increased the probability of evoking an AP in stellate cells. The raster plot illustrates that the templates with longer decay time are more successful at evoking action potentials with virtually no failures at the longest duration $(1.1 \mathrm{~ms})$. We then examined the effects of background spontaneous EPSPs on AP firing, using templates with unitary conductance (control: $1.12 \mathrm{nS}$, equivalent to $-67 \mathrm{pA}$ ). In contrast to using the double conductance, the AP firing probability was low and gradually increased as the decay time became longer (Fig. $2 C, D$ ). Thus, prolonging the decay time of synaptic currents enhances AP firing probability at double unitary conductance but has little effect as background spontaneous unitary events.

\section{Transcription-independent switch in AMPAR subtype reduces $\mathrm{EPSP}-\mathrm{AP}$ coupling}

Whereas emotional stress promotes GluR2 gene transcription in stellate cells on the order of hours, repetitive parallel fiber stimulation (300-400 stimuli) induces a rapid change in synaptic AMPAR subtype from GluR2-lacking to GluR2-containing re- 


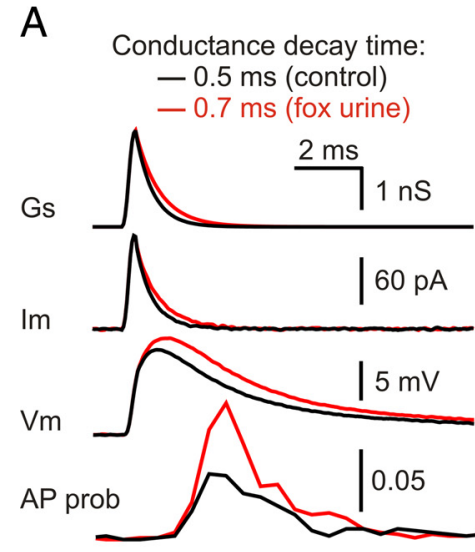

C

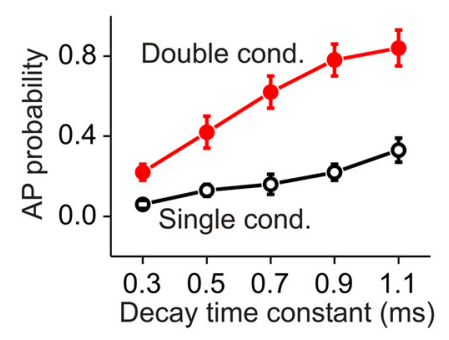

B

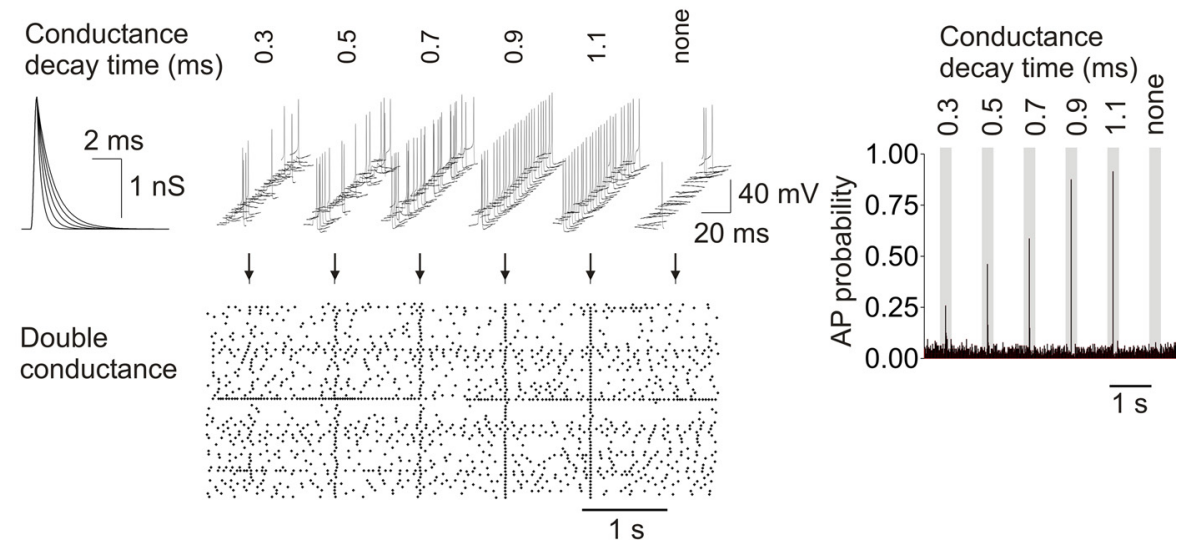

D
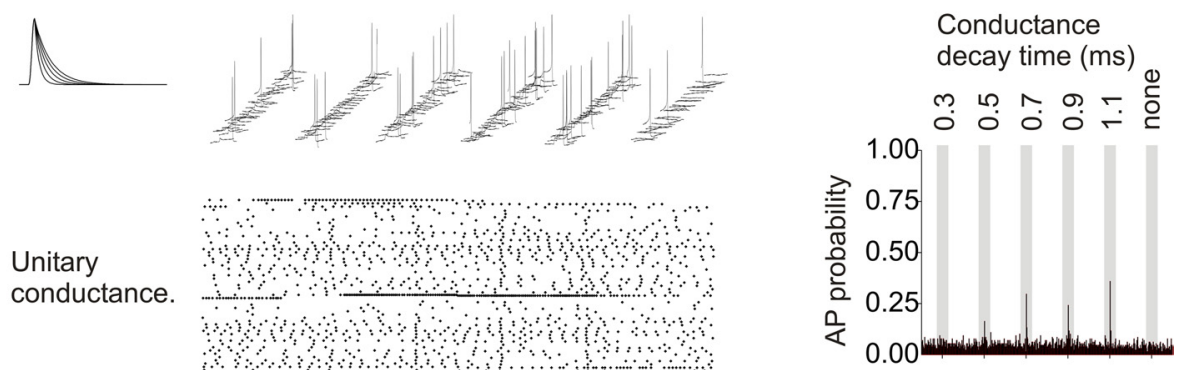

Figure 2. Increase in EPSC decay time enhanced action potential probability in stellate cells. $\boldsymbol{A}$, EPSP waveforms and action potential distributions evoked by two artificial conductance templates approximating the control and poststress EPSC decay time constant (control, $0.5 \mathrm{~ms}$; poststress, $0.7 \mathrm{~ms}$ ). The AP probability plot represents instantaneous AP probability within $0.5 \mathrm{~ms}$ bins. $\boldsymbol{B}$, Increasing EPSC decay time constant (from 0.3 to $1.1 \mathrm{~ms}$ ) increased the likelihood of evoking an action potential at the doubled conductance amplitude (equivalent to coactivation of two inputs). The raster plot shows the action potentials recorded during 60 repetitions of each conductance template (arrows). The bar graph on the right, AP probability measured in 10 ms bins. The middle of the gray bar corresponds to the time of template application. C, Summary of AP probability evoked by synaptic templates with different decay times $(n=7$; two-way ANOVA: $p<0.0001$ between unitary and double conductance; $p<0.0001$ between decay times). $D$, The effect of increasing the decay time on the probability of evoking an action potential with the unitary conductance. Raster plot shows 60 repeats of each stimulus waveform. Error bars indicate SEM.

ceptors in a transcription-independent manner (Liu and CullCandy, 2000; Liu et al., 2010). This switch is triggered by the repetitive activation of synaptic glutamate receptors and requires interaction between PICK (protein interacting with C kinase) and GluR2 subunits (Liu and Cull-Candy, 2000, 2005; Gardner et al., 2005; Sun and Liu, 2007). Incorporation of GluR2 subunits into an AMPAR is known to reduce the channel conductance (Swanson et al., 1997). When GluR2-lacking receptors are replaced with an equal number of GluR2-containing receptors, the current amplitude is reduced and the duration of EPSCs is prolonged (Liu and Cull-Candy, 2000).

In vivo recordings of cerebellar granule cells show that sensory stimulation evokes a burst of action potentials at $\sim 80 \mathrm{~Hz}$ (Chadderton et al., 2004). We determined whether a physiologically relevant stimulation can alter the synaptic AMPAR phenotype. We stimulated parallel fibers with a theta-burst-like train of four depolarizing pulses at $50 \mathrm{~Hz}$, which was repeated 10 times with an interburst interval of $2 \mathrm{~s}$ at $36^{\circ} \mathrm{C}$.

To monitor changes in the subunit composition of synaptic AMPA receptors, we included spermine in the patch electrode. Spermine blocks currents via GluR2-lacking receptors at positive membrane potentials, giving rise to an inwardly rectifying current-voltage relationship, whereas synaptic currents via GluR2containing receptors display a linear relationship. We measured spontaneous EPSCs at different potentials before and after PF stimulation. Control synaptic currents displayed an inwardly rectifying $I-V$ relationship, indicating the presence of synaptic
AMPA receptors that lack GluR2 subunits (Fig. 3A). After PF stimulation, the $I-V$ relationship changed from being inwardly rectifying to nearly linear, and the rectification index (RI) (defined as $-1.5^{\star} I_{+40} / I_{-60}$ ) increased from $0.38 \pm 0.04$ (control; $n=5$ ) to $0.74 \pm 0.09$ (30 min after PF stimulation; $n=5 ; p<$ 0.05 vs control) (Fig. $3 B$ ). The amplitude of synaptic currents at $+40 \mathrm{mV}$ increased from $15.4 \pm 0.5$ to $20.3 \pm 1.9 \mathrm{pA}(p<0.05$; $n=5$ ), indicative of an increase in GluR2-containing receptors. The EPSC amplitude at $-60 \mathrm{mV}$ decreased from $-62.0 \pm 3.5$ to $-42.2 \pm 4.8 \mathrm{pA}(p<0.05 ; n=5)$ (Fig. $3 C)$. These results suggest that GluR2-lacking synaptic AMPARs had been replaced by GluR2-containing receptors. The decay time constant of EPSCs at $-60 \mathrm{mV}$ was prolonged from $0.68 \pm 0.04$ to $0.83 \pm 0.05 \mathrm{~ms}$ $(p<0.05 ; n=5)$ (Fig. 3D). When fitted with a two-exponential function, the fast component (mediated by GluR2-lacking receptors) comprised $\sim 60 \%$ of control EPSCs but contributed little to currents after PF stimulation $(n=5 ; p<0.05)$. Thus, a physiologically relevant stimulation paradigm can induce a switch in AMPAR subtype from GluR2-lacking to GluR2-containing receptors. In contrast to the stress-induced incorporation of GluR2 receptors that prolonged EPSC decay time, the synaptic activityinduced switch is associated with a reduced synaptic conductance as well as a prolonged current decay time.

Whereas lengthening EPSC duration increased action potential firing probability (Fig. 2), a decrease in synaptic current amplitude is predicted to reduce its ability to evoke an AP. We constructed conductance templates from an average synaptic 
A

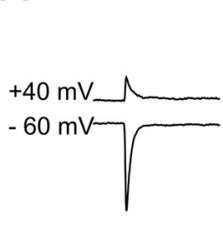

Before PF stim.

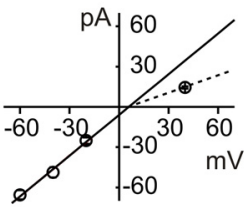

C

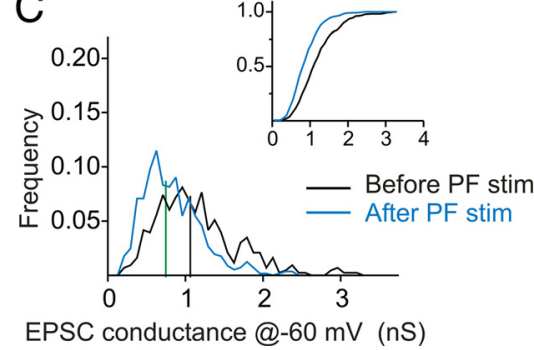

Figure 3. Theta-burst stimulation of parallel fibers induced a switch in AMPAR phenotype. $\boldsymbol{A}, \boldsymbol{B}$, Examples of average EPSC traces and $I-V$ plots before $(\boldsymbol{A})$ and after $(\boldsymbol{B})$ stimulation show a decrease in AMPAR rectification, indicating a switch of synaptic AMPARs from GluR2-lacking (GluR2-) to GluR2-containing (GluR2+) receptors. C, Relative distribution of EPSC conductance amplitudes at $-60 \mathrm{mV}$ before and after stimulation (before stimulation, 429 synaptic events; after stimulation, 562 events; $n=$ 5 cells). Inset, Cumulative distribution of amplitudes [median: $-62.8 \mathrm{pA}$ before (black line), $-46.1 \mathrm{pA}$ after (green line); $p<$ 0.00001 , Kolmogorov-Smirnov test]. D, Distribution of sEPSC decay time constant at $-60 \mathrm{mV}$ before and after the stimulation (median: 0.59 ms before, 0.73 ms after; $p<0.0001$, Kolmogorov-Smirnov test).

current before PF stimulation and reduced its amplitude to the conductance of poststimulation EPSCs without altering the decay time. As expected, we found that the AP firing probability decreased from $0.63 \pm 0.14$ to $0.38 \pm 0.16(n=4 ; p<0.05)$ (Fig. $4 A$ ) as the conductance was reduced from the prestimulation to the poststimulation amplitude $(2 \times$ unitary conductance). The unitary conductance of GluR2-lacking receptors (prestimulation, $1.12 \mathrm{nS}$ ) was then scaled by multiplying it by a factor of $0.5-5$ to cover the wide range of EPSC amplitudes that are likely to be encountered by stellate cells. Increasing the amplitude over this range consistently enhanced the ability of synaptic events to evoke APs in stellate cells (Fig. 4A). Thus, the changes in EPSC amplitude and duration that are associated with an AMPAR subtype switch produce two opposing effects on AP firing in stellate cells.

We next determined the overall effect of a switch in AMPAR subtype that is characterized by a prolonged EPSC decay time and a reduction in amplitude, on its ability to evoke AP firing in stellate cell. We used the average of EPSCs recorded before and after PF stimulation to construct conductance templates. The prestimulation (GluR2-lacking) template $(2 \times$ unitary conductance) elicited a larger EPSP than the poststimulation (GluR2containing) templates (prestimulation, $11.5 \pm 0.8 \mathrm{mV}$, vs poststimulation, $10.2 \pm 0.7 \mathrm{mV} ; n=4 ; p<0.0005)$. The poststimulation template evoked APs at a rate that was lower than that seen with the prestimulation templates (poststimulation, $0.46 \pm 0.10$, vs prestimulation, $0.54 \pm 0.10 ; n=9 ; p<0.05$ ) (Fig. $4 B)$. This was primarily attributable to the reduced EPSP amplitude as the AP probability increases with the increasing size of EPSPs $(r=0.87)$ (Fig 4C). Since a prolonged EPSC decay time promotes AP firing (Fig. 2), the decrease in EPSP-AP coupling associated with an AMPAR switch arises as a consequence of the reduced current amplitude. To test the effects of background spontaneous EPSPs on AP firing, an equal number (300) of natively occurring EPSC quantal events from several cells were recorded before and after PF stimulation and were converted to a conductance waveform. The prestimulation quantal templates
After PF stim
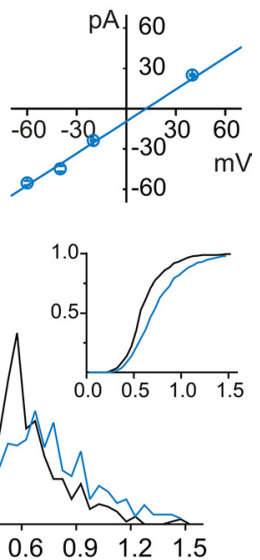

Replacing GluR2-lacking with GluR2-containing receptors abolishes postsynaptic paired-pulse facilitation

One of the possible consequences of GluR2 incorporation stems from the observation that GluR2-lacking receptors are partially blocked by intracellular polyamines at resting membrane potentials (Bowie and Mayer, 1995). This blockade can be relieved for short periods after receptor opening, giving rise to a postsynaptic paired-pulse facilitation that is absent at synapses expressing GluR2-containing receptors (Rozov et al., 1998; Rozov and Burnashev, 1999; Bagal et al., 2005). This action underlies the facilitation of the synaptic current through GluR2-lacking (but not through GluR2-containing) receptors during high-frequency synaptic stimulation. Given that the majority of parallel fiber-to-stellate cell synapses have GluR2-lacking receptors, it is possible that polyamine-dependent postsynaptic facilitation could also be present at these synapses. We therefore determined whether incorporation of GluR2 attenuates postsynaptic pairedpulse facilitation and alters short-term plasticity at the parallel fiber-to-stellate cell synapse.

The extent of postsynaptic paired-pulse facilitation was assessed by delivering paired stimuli with a $10 \mathrm{~ms}$ interval to the parallel fibers and recording the evoked synaptic currents in stellate cells. The PPRs of evoked paired EPSCs were determined at the same synapse before and after repetitive PF stimulation (Fig. $5 A$ ). It is known that the paired-pulse ratio is also sensitive to changes in presynaptic release (Zucker and Regehr, 2002). Thus, to focus on the postsynaptic component, EPSCs were evoked by threshold stimulation of presynaptic parallel fibers to minimize the potential activation of multiple inputs. The failure rate for the first of the paired pulses was $47 \pm 6 \%$, and the average EPSC amplitude was $-61.1 \pm 3.4 \mathrm{pA}$, which is within the range of the unitary EPSC amplitudes previously reported for stellate cells (Liu and Cull-Candy, 2000, 2005; Sun and Liu, 2007; Liu et al., 2010). We then also removed sweeps containing stimulation failures or multiple release events (supplemental Fig. 1, available at www.jneurosci.org as supplemental material). If this selection method does remove the presynaptic contribution to PPR, we predicted that in the absence of intracellular spermine postsynaptic paired-pulse facilitation would be absent at the parallel fiber-to-stellate cell synapse. As expected, PPR without spermine in the patch electrode was $0.99 \pm 0.04(n=5)$ (Fig. $5 B)$.

When we included spermine in the patch electrode, naive synapses had a paired-pulse ratio of $1.15 \pm 0.05(n=6)$, characteristic of a GluR2-lacking synapse (Fig. $5 A, C$ ). This value is in agreement with that reported previously (Rozov and Burnashev, 1999; Burnashev, 2005; Soto et al., 2007). After high-frequency parallel fiber stimulation, the PPR decreased to $0.96 \pm 0.07$ ( $p<$ 0.05 vs before PF stimulation; $n=6$ ) (Fig. $5 A, C$ ), consistent with the absence of polyamine block of GluR2-containing receptors. This reduction in PPR after the high-frequency parallel fiber 
A $\Delta$ cond. amplitude (without changing decay time)
B

$\Delta$ both cond. amplitude and decay time
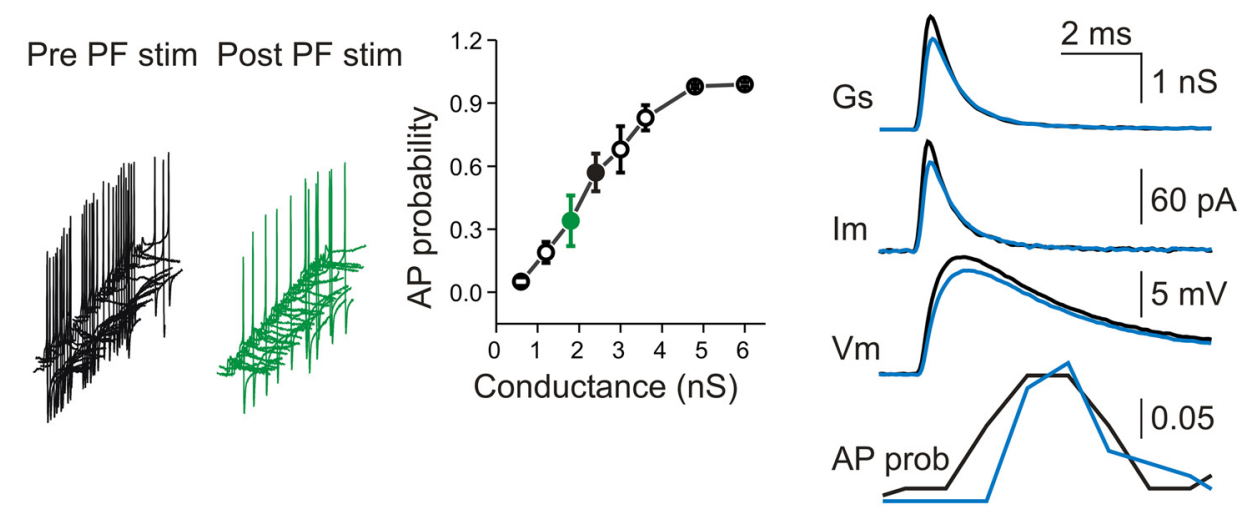
Conductance template: -Before PF stim. -After PF stim.

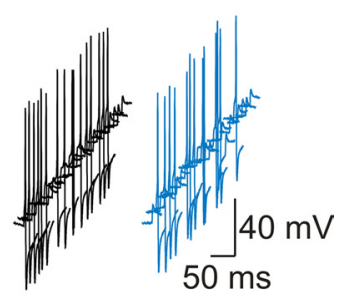

C



D
Before After

PF stim PF stim GluR2- GluR2+

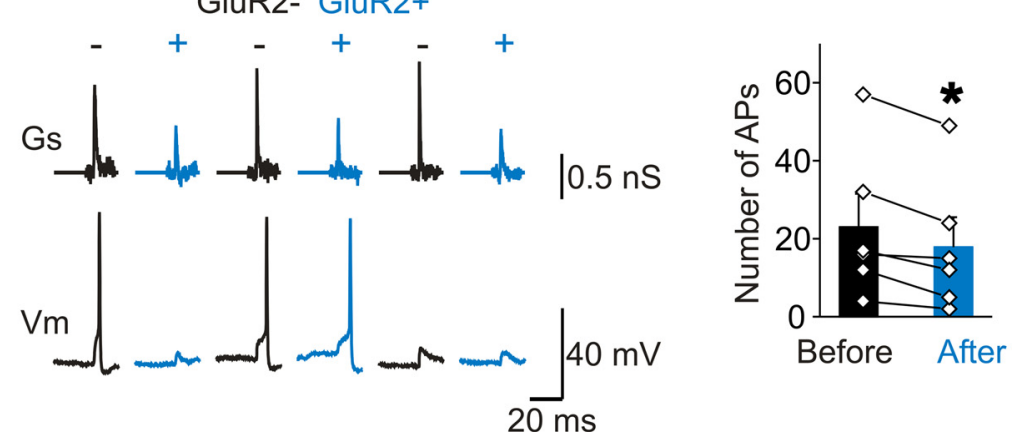

Figure 4. The theta-burst stimulation-induced change in synaptic conductance reduced the efficacy of EPSP-AP coupling. A, Left panel, Changing the amplitude (from prestimulation to poststimulation $2 \times$ unitary conductance) but not the kinetics of the synaptic conductance greatly decreased the probability of evoking an action potential. Right panel, Increasing the amplitude of the synaptic conductance increased evoked AP probability ( $p<0.00001$, ANOVA). $\boldsymbol{B}$, The average pre- and post-PF-stimulation currents were used as templates (at double their unitary size). The post-PF stimulation template produced a smaller EPSP and evoked fewer action potentials (the AP probability plot uses $0.5 \mathrm{~ms}$ bins). C, Summary of the tested conditions (Figs. $2 A, 4 B$ ) shows a linear relationship between the EPSP amplitude and the evoked AP probability (within a $20 \mathrm{~ms}$ window) $(r=0.87)$. $\boldsymbol{D}$, Action potentials were evoked by a barrage of the previously recorded prestimulation and poststimulation spontaneous synaptic conductances (GluR2 - and GluR2 + ) using dynamic current clamp. Poststimulation sEPSCs evoked fewer action potentials $(n=6 ; p<0.01)$. Error bars indicate SEM. ${ }^{*} p<0.05$.

stimulation supports the idea that a switch from GluR2-lacking to GluR2-containing receptors abolished postsynaptic pairedpulse facilitation.

The synaptic event selection method we used would not eliminate the potential presynaptic contribution because of multiple release sites. To rule out the possibility that some change unrelated to use-dependent polyamine unblock may have contributed to the attenuation of the paired-pulse ratio, we performed a control experiment in the absence of intracellular spermine. As expected, before stimulation, the recorded currents showed neither inward rectification nor paired-pulse facilitation (Fig. $5 B, D$ ). After the high-frequency parallel fiber stimulation, the rectification index and paired-pulse ratio were unchanged (before stimulation: RI, $1.06 \pm 0.16$; PPR, $0.99 \pm 0.04$; after stimulation: RI, $1.04 \pm 0.11 ; \mathrm{PPR}, 1.06 \pm 0.05 ; n=5)($ Fig. $5 D)$. This suggests that the decrease in PPR in the presence of intracellular spermine is most likely of a postsynaptic polyamine-sensitive origin, although we cannot completely rule out an additional presynaptic contribution. Thus, the activity-induced switch to GluR2-containing synapses abolishes postsynaptic facilitation at the parallel fiber-tostellate cell synapse. This indicates that the AMPAR switch is an unusual form of plasticity because in addition to evoking a longterm change in the kinetics and amplitude of synaptic currents it also affects short-term synaptic plasticity.
Paired-pulse facilitation enhances the probability that stellate cells will fire AP doublets in response to two consecutive stimuli

An in vivo study showed that sensory stimulation evokes a burst of action potentials in cerebellar granule cells that innervate stellate cells (Chadderton et al., 2004). Such burst presynaptic activity would facilitate the postsynaptic response at GluR2-lacking receptor synapses, but not at GluR2-containing synapses. We therefore examined whether these two different postsynaptic responses affected their ability to evoke AP.

Paired conductance waveforms were constructed by spacing two prestimulation GluR2-lacking or post-PF stimulation GluR2-containing average waveforms obtained from sEPSC recordings at a $10 \mathrm{~ms}$ interval. The second pulse of the GluR2lacking receptor template was scaled 1.15 times to account for the paired-pulse facilitation. The paired GluR2-lacking template of unitary conductance evoked a greater number of APs than the paired GluR2-containing template (Fig. 6A). When the first pulse evoked an AP, the second pulse nearly always failed to evoke an action potential.

We then tested whether multiple action potentials can be evoked by paired conductance waveforms that mimic coactivation of a number of inputs, using two times the unitary conductance (Fig. $6 \mathrm{~B}$ ). An action potential doublet is defined as having 
A Spermine-containing

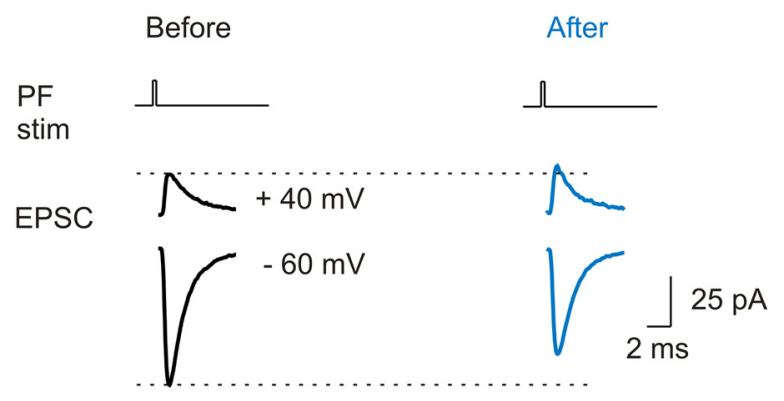

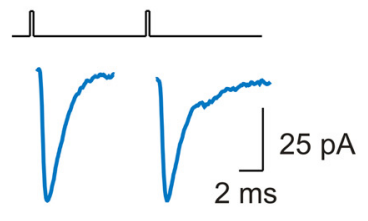

PF

stim

EPSC

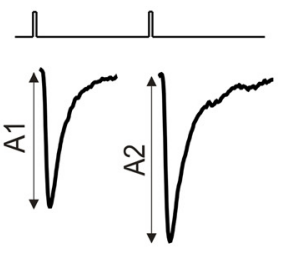

C

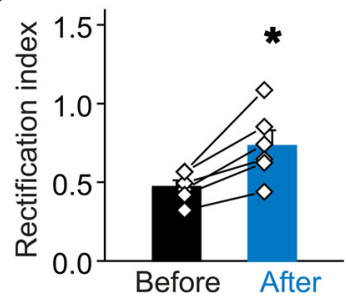

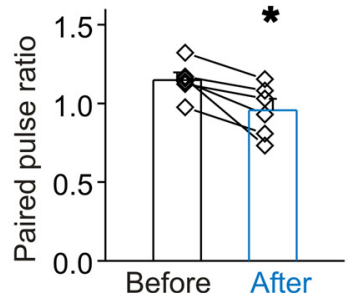

B Spermine-free
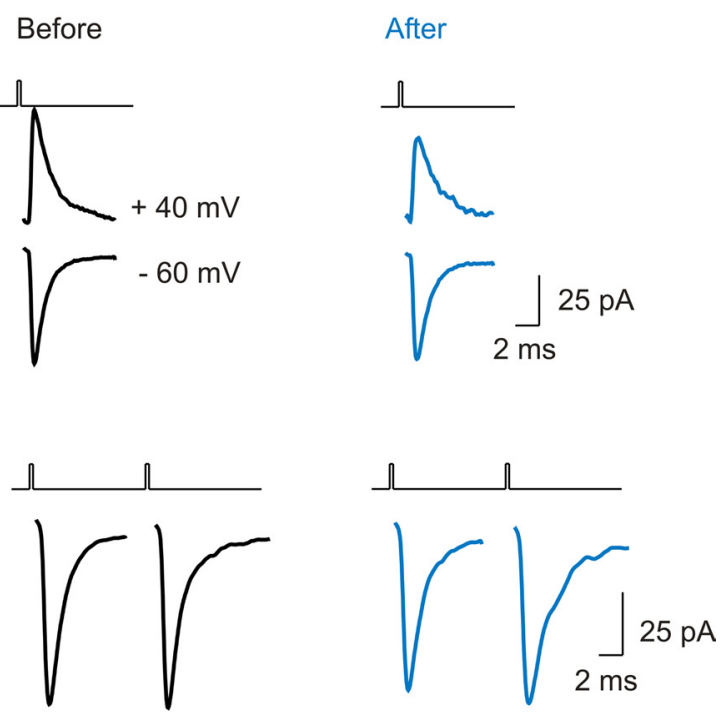

D

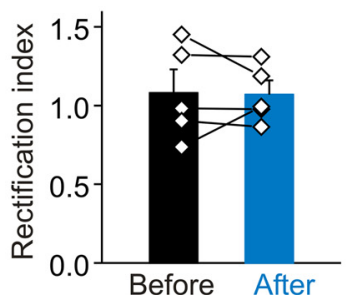

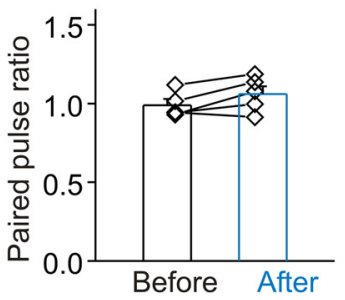

Figure 5. Presynaptic stimulation-induced incorporation of GluR2 receptors abolished spermine-dependent postsynaptic facilitation. $\boldsymbol{A}$, When spermine was included in the pipette solution, the amplitude of the synaptic current at $+40 \mathrm{mV}$ was attenuated, indicating the presence of GluR2-lacking AMPA receptors at the parallel fiber-to-stellate cell synapse. High-frequency presynaptic stimulation (HFS) induced an increase in the EPSC amplitude at $+40 \mathrm{mV}$ and a decrease at $-60 \mathrm{mV}$. HFS also abolished postsynaptic paired-pulse facilitation that was observed at the naive synapse (A2/A1). $\boldsymbol{B}$, In the absence of spermine, the synaptic current exhibited a linear $/-V$ relationship even before stimulation. HFS did not alter the paired-pulse ratio. $C$, Summary of HFS-induced changes in rectification index $\left(n=6\right.$; $\left.{ }^{*} p<0.01\right)$ and paired-pulse ratio $\left(n=6 ;{ }^{*} p<0.05\right)$ in the presence of intracellular spermine. $D$, Summary of rectification index and paired-pulse ratio changes in the absence of intracellular spermine $(n=5)$. Error bars indicate SEM.

an action potential in a $10 \mathrm{~ms}$ window after the first pulse, and another AP within a $60 \mathrm{~ms}$ window after the second pulse. These criteria were chosen from inspection of the peristimulus time histogram (Fig. 6C). We observed that the probability that a GluR2-lacking paired conductance waveform evoked an action potential doublet was greater than the GluR2-containing waveform $(28.5 \pm 6.4$ vs $10.3 \pm 3.2 \% ; p<0.001 ; n=7)($ Fig. $6 B, D)$. This is primarily attributable to a greater amplitude of the EPSP elicited by the GluR2-lacking paired conductance waveform, relative to GluR2-containing waveform (second EPSP: GluR2-lacking, $15.3 \pm 0.9 \mathrm{mV}$, vs GluR2-containing, $12.6 \pm 0.8 \mathrm{mV} ; n=4 ; p<$ 0.001) (Fig. 6B). Thus a PF stimulation-induced switch in AMPA receptor phenotype can reduce the frequency and alter the firing pattern of evoked action potentials in stellate cells.

The AMPAR switch not only abolishes postsynaptic facilitation but also reduces the current amplitude and prolongs the decay time. To test the importance of postsynaptic facilitation in evoking double action potentials, we systematically scaled up the second pulse of the GluR2-lacking templates from 0 to $20 \%$. As shown in Figure $6 D$, the presence of postsynaptic facilitation significantly enhanced the probability of evoking a doublet. Overall, EPSP amplitude of the second pulse appears to determine the probability of evoking a doublet action potential (linear fit to several tested conditions, $r=0.997$ ) (Fig. 7C).

Stress-induced incorporation of GluR2 receptors prolongs EPSC decay time but does not alter current amplitude. To exam- ine the effect on the action potential firing pattern, we constructed a poststress paired conductance template from an average EPSC (rather than a template with a decay time that corresponds to the median decay time constant after fear stimulus). This template had a prolonged decay time $(0.75 \mathrm{~ms}$; control, $0.65 \mathrm{~ms}$ ) but the same conductance amplitude as the control without facilitation (Fig. 7). We reasoned that the probability of evoking a doublet was likely to be reduced because of the lack of facilitation, but enhanced by the prolonged decay time, and that these two opposing effects may cancel each other out. Indeed, the probability for the paired poststress conductance waveform to evoke an action potential doublet was not significantly different from the control GluR2-lacking waveform (poststress, 31.6 $\pm 7.7 \%$, vs control, $33.0 \pm 6.8 \% ; p=0.3$, paired $t$ test; $n=7$ ) (Fig. $7 B$ ). This was primarily attributable to the amplitude of the membrane depolarization being similar under the two tested conditions (second EPSP, poststress: $16.9 \pm 1.7 \mathrm{mV}$; control GluR2-lacking waveform with $15 \%$ facilitation: $17.1 \pm 1.7 ; n=4$ ) (Fig. $7 C$ ). However, the doublet action potentials evoked by the poststress paired conductance displayed a slightly longer delay of the second AP relative to control (GluR2-lacking and 15\% facilitation; $40.3 \pm 4.0 \mathrm{~ms}$; poststress, $42.6 \pm 4.2 \mathrm{~ms} ; n=7 ; p<0.05)$.

Therefore, these two physiological stimulus-induced changes in EPSC waveforms produce distinct alterations in action potential firing. The stress-induced incorporation of GluR2 receptors markedly enhances the action potential firing probability but 
does not alter the firing pattern in response to two consecutive synaptic inputs. In contrast, the PF stimulation-induced switch in AMPAR phenotype reduces the action potential firing probability and abolishes the ability of the paired conductance waveform to evoke an action potential doublet.

\section{Discussion}

Experience can alter synaptic AMPAR subtype in several brain regions (Liu and Cull-Candy, 2000; Bellone and Lüscher, 2006; Clem and Barth, 2006; Goel et al., 2006; Plant et al., 2006). In cerebellar stellate cells, two different physiological stimuli, a fear-inducing stimulus and PF activity that mimic sensory stimulation, both increase synaptic GluR2-containing receptors but produce distinct changes in EPSC waveforms. Fear-inducing stimulus increases GluR2 gene transcription and promotes synaptic GluR2-containing receptor expression on the order of hours (Liu et al., 2010). This prolongs the decay time of the EPSCs without changing the current amplitude at $-60 \mathrm{mV}$. Here, we show that the prolonged decay time produced a marked increase in AP firing probability. In contrast, a thetaburst-like PF stimulation induced a rapid change from GluR2-lacking to GluR2containing AMPARs at the PF-to-stellate cell synapse. The switch in AMPAR phenotype reduced the amplitude and lengthened the decay kinetic of EPSCs (Liu and CullCandy, 2000), and led to a reduction in the EPSP-AP coupling frequency, which was primarily attributable to the decrease in EPSC amplitude. Furthermore, postsynaptic paired-pulse facilitation, a form of shortterm plasticity, at cerebellar synapses enabled stellate cells to fire doublet APs. The switch in AMPAR subtype abolished postsynaptic paired-pulse facilitation, and thus two consecutive EPSCs evoked only single APs. Therefore, two physiologically relevant stimuli alter synaptic AMPAR phenotype via different mechanisms and produce distinct functional consequences; a stress-induced incorporation of GluR2 receptors enhances the EPSP-AP coupling, whereas a PF stimulation-triggered switch in AMPAR phenotype reduces EPSP-AP coupling and alters the pattern of APs in response to a burst of synaptic activity.

PF stimulation reduced EPSC amplitude at $-60 \mathrm{mV}$ by $32 \%$. The similarity between this and a $30 \%$ reduction in the average single-channel conductance of $\mathrm{Ca}^{2+}$-impermeable AMPARs, relative to that of a mixture of both types of receptors (Liu and Cull-Candy, 2005), suggests that the total number of synaptic receptors is not greatly altered ("switch"). In keeping with this idea, control EPSCs mediated by a mixture of receptors contain both fast $(\sim 60 \%)$ and slow components, but only the slow component contributed to currents after PF stimulation. In contrast, fear stimulus did not alter EPSC amplitude at $-60 \mathrm{mV}$, which suggests an increase in the total number of synaptic receptors by bars indicate SEM.

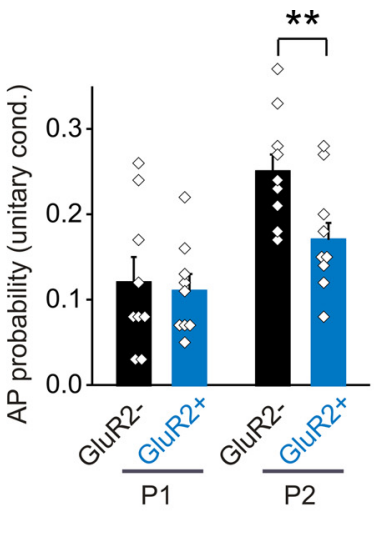

C

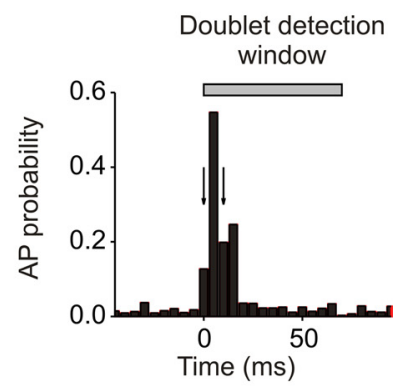

After PF stim

(GluR2+, no fac)
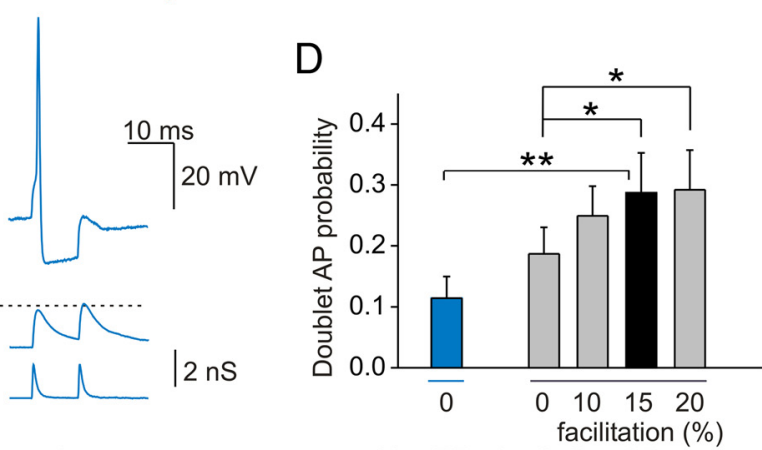

After PF stim Before PF stim

(GluR2+) (GluR2-)

Figure 6. Changes in postsynaptic facilitation altered the pattern of AP firing evoked by paired inputs. $\boldsymbol{A}$, Test of the ability of (he time of paired conductance application). Right panel, Prestimulation, GluR2-lacking (GluR2-) unitary paired 列 stimulation train are marked with red symbols in the raster plot. C. An example plot of AP probability demonstrating the doublet postsynaptic facilitation enhances doublet AP probability for the GluR2-lacking template $\left(n=7 ;{ }^{*} p<0.05,{ }^{* *} p<0.001\right)$. Error

$\sim 36 \%$ ("incorporation"). This is probably attributable to the insertion of newly synthesized GluR2 receptors since the current amplitude at $+40 \mathrm{mV}$ increased by $70 \%$ (Liu et al., 2010). The fast component still comprised $\sim 30 \%$ of the total synaptic current. These results indicate that fear stimulus markedly promotes the insertion of GluR2 receptors and moderately reduces $\mathrm{Ca}^{2+}$ permeable receptors, therefore preserving the EPSC amplitude at $-60 \mathrm{mV}$.

The spontaneous synaptic conductances that were recorded in physiologically relevant conditions displayed a wide range of amplitudes, all of which were found to be within the linear range of the input-output curve for stellate cells. The majority of single spontaneous events fail to evoke an action potential. However, simultaneous activation of multiple inputs (two or more coincident inputs) can more reliably trigger AP firing, consistent with previous reports (Carter and Regehr, 2002). The coincident re- 
A Control After Fox urine (predicted)
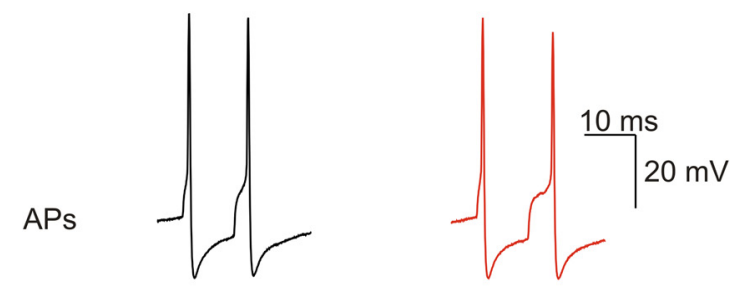

$\mathrm{B}$

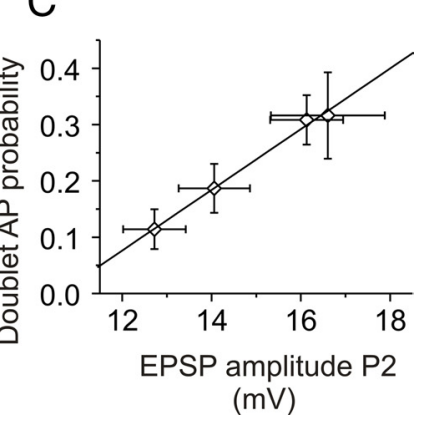

Figure 7. The stress-induced incorporation of GluR2 receptors did not alter the ability of the paired conductance waveform to evoke an action potential doublet. $A$, Examples of EPSPs and APs evoked by naive (control, GluR2-lacking with 15\% facilitation) and poststress-like paired conductance templates at double the unitary conductance. Doublets are marked in red on the raster plot. $\boldsymbol{B}$, Doublet AP probability evoked by paired control and simulated post-fox urine templates $(n=7)$. C, Summary of the tested conditions (data in Figs. $6 D, 7 A$ ) showing a strong correlation between the amplitude of the second EPSP and the probability of doublet AP (linear fit, $r=0.99$ ). Error bars indicate SEM.

lease of two quanta increased the likelihood of AP firing from 20 to $60 \%$, and four synchronous quantal events further enhanced the efficacy to $>90 \%$. Thus, the stellate cell input-output curve is tuned to a range that allows them to mostly "ignore" spontaneous release noise (small sEPSCs) yet fire reliably in response to as few as two coincident inputs.

We find that incorporation of GluR2-containing receptors at a synapse that normally expresses GluR2-lacking receptors prolongs the EPSC decay time constant. This is consistent with earlier observations that GluR2-containing receptors have slower kinetics (Burnashev et al., 1992; Mosbacher et al., 1994; Geiger et al., 1995; Gardner et al., 1999). This change in kinetics contrasts with long-term potentiation and depression that is associated with alterations in the amplitude but not the decay time of synaptic currents. The small increase in decay time (from 0.5 to 0.7 $\mathrm{ms}$ ) that is associated with the insertion of GluR2 produced a marked increase in the probability of evoking an AP (by 50\%). Thus, stellate cells are tuned to the physiologically relevant range of EPSC kinetics. They are particularly sensitive to changes in decay time that are mediated by the insertion of GluR2. We have recently found that a fear-inducing stimulus, which causes the release of noradrenaline, activates $\beta$-adrenergic receptors and drives GluR2 gene expression and synaptic incorporation of GluR2-containing AMPARs (Liu et al., 2010). This gives rise to a prolonged decay time of EPSCs and thereby enhances AP firing in stellate cells.

Whereas fear-inducing stimulus selectively lengthens EPSCs, PF stimulation-induced switch in AMPAR subtype not only prolongs EPSC decay time but also reduces the current amplitude at $-60 \mathrm{mV}$. Indeed, poststimulation synaptic current via GluR2containing receptors became less effective at triggering an $\mathrm{AP}$ and consequently an increased number of coincident quantal events

(from 2 to 2.5 quanta) would be required to trigger stellate cell firing $\sim 60 \%$ of the time. However, no difference was observed in response to more than four synchronous quanta as the probability of evoking AP reached a plateau (data not shown). Thus, a switch in AMPAR phenotype is expected to alter the synaptic computation in response to a few synaptic inputs.

Granule cells fire a burst of APs in response to sensory stimulation (Chadderton et al., 2004). Although short-term presynaptic facilitation is known to enhance synaptic transmission in stellate cells (Chen and Regehr, 1999), our results indicate that paired presynaptic stimuli can also produce different postsynaptic responses in stellate cells depending on the subunit composition of AMPARs (although the relative contribution from presynaptic and postsynaptic loci is unclear). Postsynaptic facilitation was observed at cerebellar synapses containing GluR2lacking receptors but was abolished after PF stimulation when the synaptic receptors changed to GluR2-containing receptors. This is consistent with the reports that postsynaptic paired-pulse facilitation only occurs at synapses expressing GluR2lacking receptors (Rozov et al., 1998; Rozov and Burnashev, 1999; Bagal et al., 2005). The postsynaptic facilitation not only enhances the AP probability but also enables the postsynaptic stellate cells to fire two APs in response to paired stimuli. In contrast, paired EPSCs that mimic the GluR2-containing receptor current after the PF stimulation evoked fewer APs and failed to evoke doublets. The generation of two APs by a pair of stimuli would therefore enhance GABA release from stellate cells and produce more powerful inhibitory effects on postsynaptic Purkinje cells and other synaptically connected stellate cells (Häusser and Clark, 1997; Lachamp et al., 2009).

Postsynaptic facilitation at $\mathrm{Ca}^{2+}$-permeable synapses occurs only during repetitive activation of the same synapse that triggers the use-dependent polyamine unblock. This contrasts with the purely coincident inputs coming from different synapses that give rise to two consecutive, but independent synaptic events (e.g., GluR2-lacking paired conductance waveform without facilitation). Thus, the large effect of postsynaptic facilitation on the firing pattern may allow stellate cells to distinguish between two randomly coincident EPSCs and a burst input originating from the same synaptic input.

Inhibitory transmission in the cerebellum is thought to be critically involved in cerebellar learning and memory (Scelfo et al., 2008; Wulff et al., 2009). The firing pattern of stellate/basket cells controls the timing and firing frequency of Purkinje cells (Midtgaard, 1992; Häusser and Clark, 1997; Jaeger and Bower, 1999). Our results indicate that an activity-dependent remodeling of AMPAR subtype can alter the stellate cell AP firing probability and pattern in response to a few synaptic inputs. Emotional stress-induced incorporation of GluR2 receptors increases the AP firing probability without compromising its ability to evoke AP doublets. This is expected to enhance the feedforward inhibition of Purkinje cell activity. In contrast, PF stimulation induced 
a switch in AMPAR phenotype that reduced the AP firing probability and the ability of paired stimuli to evoke two consecutive APs. These changes would reduce inhibitory transmission onto Purkinje cells in response to the burst activity of granule cells that occurs during sensory stimulation (Chadderton et al., 2004). Thus, alterations in synaptic AMPAR phenotype in stellate cells are likely to influence the AP firing of Purkinje cells and would be expected to have a profound effect on cerebellar network activity.

AMPAR subtype remodeling has been widely observed in several brain regions under physiological and pathological conditions (Liu and Zukin, 2007). Recent studies show that the association of AMPARs with transmembrane AMPA receptor regulatory protein (TARP) and CKAMP44 also prolongs the decay kinetics and alters postsynaptic paired-pulse facilitation of AMPA currents (Tomita et al., 2005; Cho et al., 2007; Milstein et al., 2007; Morimoto-Tomita et al., 2009; von Engelhardt et al., 2010). Thus, our results suggest that enhanced AMPAR-TARP interactions could also strengthen EPSP-AP coupling. Our finding that both the waveform and postsynaptic paired-pulse facilitation of synaptic conductance are critical in controlling AP firing highlights the functional importance of activitydependent changes in AMPAR phenotype and of AMPAR regulatory proteins.

\section{References}

Bagal AA, Kao JP, Tang CM, Thompson SM (2005) Long-term potentiation of exogenous glutamate responses at single dendritic spines. Proc Natl Acad Sci U S A 102:14434-14439.

Barry MF, Ziff EB (2002) Receptor trafficking and the plasticity of excitatory synapses. Curr Opin Neurobiol 12:279-286.

Bellone C, Lüscher C (2006) Cocaine triggered AMPA receptor redistribution is reversed in vivo by mGluR-dependent long-term depression. Nat Neurosci 9:636-641.

Bowie D, Mayer ML (1995) Inward rectification of both AMPA and kainate subtype glutamate receptors generated by polyamine-mediated ionchannel block. Neuron 15:453-462.

Burnashev N (2005) Dynamic modulation of AMPA receptor-mediated synaptic transmission by polyamines in principal neurons. Focus on "Polyamines modulate AMPA receptor-dependent synaptic response in immature layer V pyramidal neurons." J Neurophysiol 93:2371.

Burnashev N, Monyer H, Seeburg PH, Sakmann B (1992) Divalent ion permeability of AMPA receptor channels is dominated by the edited form of a single subunit. Neuron 8:189-198.

Carter AG, Regehr WG (2002) Quantal events shape cerebellar interneuron firing. Nat Neurosci 5:1309-1318.

Chadderton P, Margrie TW, Häusser M (2004) Integration of quanta in cerebellar granule cells during sensory processing. Nature 428:856-860.

Chen C, Regehr WG (1999) Contributions of residual calcium to fast synaptic transmission. J Neurosci 19:6257-6266.

Cho CH, St-Gelais F, Zhang W, Tomita S, Howe JR (2007) Two families of TARP isoforms that have distinct effects on the kinetic properties of AMPA receptors and synaptic currents. Neuron 55:890-904.

Clem RL, Barth A (2006) Pathway-specific trafficking of native AMPARs by in vivo experience. Neuron 49:663-670.

Cull-Candy S, Kelly L, Farrant M (2006) Regulation of $\mathrm{Ca}^{2+}$-permeable AMPA receptors: synaptic plasticity and beyond. Curr Opin Neurobiol 16:288-297.

Fitzgerald LW, Ortiz J, Hamedani AG, Nestler EJ (1996) Drugs of abuse and stress increase the expression of GluR1 and NMDAR1 glutamate receptor subunits in the rat ventral tegmental area: common adaptations among cross-sensitizing agents. J Neurosci 16:274-282.

Gardner SM, Trussell LO, Oertel D (1999) Time course and permeation of synaptic AMPA receptors in cochlear nuclear neurons correlate with input. J Neurosci 19:8721-8729.

Gardner SM, Takamiya K, Xia J, Suh JG, Johnson R, Yu S, Huganir RL (2005) Calcium-permeable AMPA receptor plasticity is mediated by subunitspecific interactions with PICK1 and NSF. Neuron 45:903-915.

Geiger JR, Melcher T, Koh DS, Sakmann B, Seeburg PH, Jonas P, Monyer H
(1995) Relative abundance of subunit mRNAs determines gating and $\mathrm{Ca}^{2+}$ permeability of AMPA receptors in principal neurons and interneurons in rat CNS. Neuron 15:193-204.

Goel A, Jiang B, Xu LW, Song L, Kirkwood A, Lee HK (2006) Cross-modal regulation of synaptic AMPA receptors in primary sensory cortices by visual experience. Nat Neurosci 9:1001-1003.

Grooms SY, Opitz T, Bennett MV, Zukin RS (2000) Status epilepticus decreases glutamate receptor $2 \mathrm{mRNA}$ and protein expression in hippocampal pyramidal cells before neuronal death. Proc Natl Acad Sci U S A 97:3631-3636.

Häusser M, Clark BA (1997) Tonic synaptic inhibition modulates neuronal output pattern and spatiotemporal synaptic integration. Neuron 19:665-678.

Isaac JT, Ashby M, McBain CJ (2007) The role of the GluR2 subunit in AMPA receptor function and synaptic plasticity. Neuron 54:859-871.

Jaeger D, Bower JM (1999) Synaptic control of spiking in cerebellar Purkinje cells: dynamic current clamp based on model conductances. J Neurosci 19:6090-6101.

Kopec CD, Kessels HW, Bush DE, Cain CK, LeDoux JE, Malinow R (2007) A robust automated method to analyze rodent motion during fear conditioning. Neuropharmacology 52:228-233.

Lachamp PM, Liu Y, Liu SJ (2009) Glutamatergic modulation of cerebellar interneuron activity is mediated by an enhancement of GABA release and requires protein kinase A/RIMlalpha signaling. J Neurosci 29:381-392.

Liu SJ, Cull-Candy SG (2005) Subunit interaction with PICK and GRIP controls $\mathrm{Ca}^{2+}$ permeability of AMPARs at cerebellar synapses. Nat Neurosci 8:768-775.

Liu SJ, Zukin RS (2007) $\mathrm{Ca}^{2+}$-permeable AMPA receptors in synaptic plasticity and neuronal death. Trends Neurosci 30:126-134.

Liu SQ, Cull-Candy SG (2000) Synaptic activity at calcium-permeable AMPA receptors induces a switch in receptor subtype. Nature 405:454-458.

Liu Y, Formisano L, Savtchouk I, Takayasu Y, Szabó G, Zukin RS, Liu SJ (2010) A single fear-inducing stimulus induces a transcriptiondependent switch in synaptic AMPAR phenotype. Nat Neurosci 13:223-231.

Malinow R, Malenka RC (2002) AMPA receptor trafficking and synaptic plasticity. Annu Rev Neurosci 25:103-126.

Midtgaard J (1992) Stellate cell inhibition of Purkinje cells in the turtle cerebellum in vitro. J Physiol 457:355-367.

Milstein AD, Zhou W, Karimzadegan S, Bredt DS, Nicoll RA (2007) TARP subtypes differentially and dose-dependently control synaptic AMPA receptor gating. Neuron 55:905-918.

Morimoto-Tomita M, Zhang W, Straub C, Cho CH, Kim KS, Howe JR, Tomita S (2009) Autoinactivation of neuronal AMPA receptors via glutamate-regulated TARP interaction. Neuron 61:101-112.

Mosbacher J, Schoepfer R, Monyer H, Burnashev N, Seeburg PH, Ruppersberg JP (1994) A molecular determinant for submillisecond desensitization in glutamate receptors. Science 266:1059-1062.

Opitz T, Grooms SY, Bennett MV, Zukin RS (2000) Remodeling of $\alpha$-amino-3-hydroxy-5-methyl-4-isoxazole-propionic acid receptor subunit composition in hippocampal neurons after global ischemia. Proc Natl Acad Sci U S A 97:13360-13365.

Plant K, Pelkey KA, Bortolotto ZA, Morita D, Terashima A, McBain CJ, Collingridge GL, Isaac JT (2006) Transient incorporation of native GluR2-lacking AMPA receptors during hippocampal long-term potentiation. Nat Neurosci 9:602-604.

Rozov A, Burnashev N (1999) Polyamine-dependent facilitation of postsynaptic AMPA receptors counteracts paired-pulse depression. Nature 401:594-598.

Rozov A, Zilberter Y, Wollmuth LP, Burnashev N (1998) Facilitation of currents through rat $\mathrm{Ca}^{2+}$-permeable AMPA receptor channels by activity-dependent relief from polyamine block. J Physiol 511:361-377.

Scelfo B, Sacchetti B, Strata P (2008) Learning-related long-term potentiation of inhibitory synapses in the cerebellar cortex. Proc Natl Acad Sci U S A 105:769-774.

Song I, Huganir RL (2002) Regulation of AMPA receptors during synaptic plasticity. Trends Neurosci 25:578-588. 
Soto D, Coombs ID, Kelly L, Farrant M, Cull-Candy SG (2007) Stargazin attenuates intracellular polyamine block of calcium-permeable AMPA receptors. Nat Neurosci 10:1260-1267.

Sun L, Liu SJ (2007) Activation of extrasynaptic NMDA receptors induces a PKC-dependent switch in AMPA receptor subtypes in mouse cerebellar stellate cells. J Physiol 583:537-553.

Swanson GT, Kamboj SK, Cull-Candy SG (1997) Single-channel properties of recombinant AMPA receptors depend on RNA editing, splice variation, and subunit composition. J Neurosci 17:58-69.

Tomita S, Adesnik H, Sekiguchi M, Zhang W, Wada K, Howe JR, Nicoll RA, Bredt DS (2005) Stargazin modulates AMPA receptor gating and trafficking by distinct domains. Nature 435:1052-1058.
Trussell L (1998) Control of time course of glutamatergic synaptic currents. Prog Brain Res 116:59-69.

von Engelhardt J, Mack V, Sprengel R, Kavenstock N, Li KW, Stern-Bach Y, Smit AB, Seeburg PH, Monyer H (2010) CKAMP44: a brain-specific protein attenuating short-term synaptic plasticity in the dentate gyrus. Science 327:1518-1522.

Wulff P, Schonewille M, Renzi M, Viltono L, Sassoè-Pognetto M, Badura A, Gao Z, Hoebeek FE, van Dorp S, Wisden W, Farrant M, De Zeeuw CI (2009) Synaptic inhibition of Purkinje cells mediates consolidation of vestibulo-cerebellar motor learning. Nat Neurosci 12:1042-1049.

Zucker RS, Regehr WG (2002) Short-term synaptic plasticity. Annu Rev Physiol 64:355-405. 